\title{
Childhood Leukemia Not Linked with ELF Magnetic Fields
}

\author{
Norbert Leitgeb \\ Institute of Health Care Engineering with European Notified Body of Medical Devices, Graz University of \\ Technology, Graz, Austria \\ Email: norbert.leitgeb@tugraz.at
}

Received 21 April 2014; revised 18 May 2014; accepted 13 June 2014

Copyright (C) 2014 by author and Scientific Research Publishing Inc.

This work is licensed under the Creative Commons Attribution International License (CC BY).

http://creativecommons.org/licenses/by/4.0/

(c) (i) Open Access

\begin{abstract}
The discussion whether extremely low frequency (ELF) magnetic fields (MF) are causally linked with childhood leukemia is ongoing for almost four decades. Results of epidemiologic studies have indicated such an association might exist and led to IARC's classification of ELF MF as possibly carcinogenic (class 2B). Although in the meanwhile many epidemiologic studies and meta-analyses of selected studies are available, this did not change the situation. By a new approach of pooling all epidemiologic data, this paper shows that it is possible to come to a convincing conclusion which explains controversial results and reports dose-response relationship, and provides answers to striking facts such as that epidemiologic results on childhood leukemia are independent from field source or exposure metric of whatever kind with no specific favorite. The analysis revealed that the assumption of a causal link between ELF MF exposure and childhood leukemia is no longer plausible and hence that ELF MF's classification as possibly carcinogenic needs revision.
\end{abstract}

\section{Keywords}

Health Risk Assessment, Long-Term Exposure, Cancer, Safety, Power Line

\section{Introduction}

Research on health risks of extremely low frequencies (ELF) magnetic fields (MF) in particular with regard to childhood leukemia is ongoing already for more than four decades. In spite of this, it is still considered unclear whether or not a causal link exists. However, ELF MF are suspected to be possibly carcinogenic by the International Agency for Research on Cancer (IARC) of the World Health Organization (WHO) [1].

In the past decades, the knowledge on physical nature of ELF MF as well as their physical and biological interaction mechanism has been well established. It is known that exposure to magnetic fields may cause 
adverse health effects in terms of stimulation of nerve and muscle cells, provided they are sufficiently strong to exceed cellular excitation thresholds. Consequently, such bioeffects can be excluded rather than just minimized if the excess of excitation thresholds is prevented [2]-[4].

The necessary precondition for health effects of long-term exposure to weak ELF MF would be either the production of small persisting changes which could sum up over time until adverse levels ("dose-" effect) and/or the existence of effects with transient times long enough to cause additive crossover effects in case of intermittent exposures. However, established knowledge and experimental data do not provide evidence for this. Consequently, there is no support for the hypothesis that specific effects long-term exposure to weak ELF MF could exist such as induction of cancer or childhood leukemia.

In spite of this, it was in 1979 when the first case-control epidemiological study reported on a statistical significant association between childhood leukemia and exposure to residential ELF MF from electric utility cables as quantified by a surrogate, namely a "wiring code" which accounted for the number of overhead cables, their thickness and distance from homes [5]. In the following decades, numerous attempts have been made to verify this epidemiological finding. Neither in adults nor in children could a statistical association be found with cancer in general. However, epidemiological studies on childhood leukemia generated results which exhibited a tendency towards an increased risk although convincing evidence for this is still lacking. Even several pooled analyses failed to clarify the situation [6]-[9].

In this situation, based on just epidemiological evidence at power frequency the IARC classified magnetic fields in the entire range of extremely low frequencies as "possibly carcinogenic" class 2B [1], and in regulations authorities included disclaimers that exposure limits would not address "the long-term effects" including possible carcinogenic effects by arguing that "currently" there would be no conclusive scientific evidence establishing a causal relationship [2] [4]. However, it has been added that if such evidence emerged, appropriate actions would be taken thus suggesting that this was a plausible expectation [4].

The World Health Organization concluded "there is no consistent evidence that exposure to environmental ELF fields cause direct damage to molecules including DNA", hence it is "unlikely that they may initiate cancer". However, it was cryptically added that "the consistent (epidemiological) pattern of increased risk for childhood leukemia, on balance provided not strong enough evidence for causality but for remaining concern" [3].

Since 1979 epidemiologic studies used a wide variety of approaches to characterize exposure to ELF MF. Since there is no mechanism on which a metric for long-term exposure could be based upon, in a look-and-see approach many studies calculated odds ratios for many different exposure parameters.

In this paper, the existing body of epidemiological data is analyzed based on a new approach. While past attempts concentrated on meta-analyses and, hence, faced the problem to be restricted to subgroups of studies with similar design, in particular with similar dose metrics, this new approach does not need to exclude any study but allows including all existing data. It is able to provide new insights and more reliable conclusions.

\section{Method}

Since there is no basis to decide which exposure metric is adequate, in this analysis no selection of epidemicologic childhood studies was made, and all published data are assessed in a pooled approach.

The body of epidemiologic data was analyzed based on the following working hypotheses:

1) Since scientific experience should have increased in the past 35 years since 1979, it should be expected that methodology has been improved with time, and if there is a causal relationship, results should tend towards a final value, indicating either increased, decreased risk or lack of an association.

2) Since the power of a study should increase with the number of investigated exposed cases, the reliability of results should increase with increased numbers of cases e.g. childhood leukemia or cancer.

Consequently, the published odds ratios were analyzed as a function of publication time and as a function of the number of exposed cases to see whether the overall pattern of results gained within the past 35 years allow drawing conclusions.

\section{Results}

In contrast to meata-analyses where only a limited number of studies were pooled such as 4 [6], 9 [4], 10 [9] or 12 [5], in this approach, the reported epidemiologic studies on childhood leukemia and other childhood cancer 
were analyzed without any exclusion thus making use of a much larger body of evidence.

The analysis of potential dependence on time of reported odds ratios (OR) of 36 childhood leukemia epidemiological studies showed that there is no time trend (Figure 1) [5]-[40]. Therefore, it needs to be concluded that improvements in study design such as accounting for historical fields, evaluating long-term records of electric currents of power lines or differentiating between nighttime and daytime exposure etc. did not result in a time trend, neither of statistical significant nor iof statistical not significant results (Figure 1). It can be seen that significant odds ratios are found above the no-risk-line $\mathrm{OR}=1$ indicating enhanced risk as well as below it, indicating reduced risk, and that the number of significant results above 1 is higher. However, it needs to be noted that the term "significance" needs to be interpreted with care because studies did not apply Bonferroni corrections in terms of adjusting the level of significance for multi-parameter testing. Overall, taken the significant and non-significant results together, there is an offset of the body of results towards increased risk. This has been interpreted as a reason for health concern [1]-[4].

The pooled odds ratios (OR) reported in 13 studies on childhood cancer (except childhood leukemia) [33]-[48] including a meta-analysis of 16 of these studies [9] are shown in Figure 2 in dependence on the number of exposed cases $\mathrm{N}_{\text {cases }}$. Please note that the number of OR is much higher than the number of studies because studies usually apply different exposure parameters and conditions and consequently report many OR values. Similar to the data on childhood leukemia it can be seen that results can be found on either side of the no-risk-line $\mathrm{OR}=1$. Again, there is an offset of the body of results towards increased risk $(\mathrm{OR}>1)$. Again, there are statistical significant OR values larger than 1 . However, it is interesting to note that these are restricted to studies with only few exposed cases (small $\mathrm{N}_{\text {cases }}$ ). The meta-analysis of 10 studies did not report statistical significant OR. Overall, scientific risk analyses concluded, that there is no association between ELF MF exposures and childhood cancer [1] [3].

The same approach was applied to the reported It is important to note that the overall pattern of OR values is in agreement with the conclusion, that there is no causal link. It can be seen that with increasing $\mathrm{N}_{\text {cases }}$ from either side OR values tend towards the no-risk-line $\mathrm{OR}=1$, and they clearly stay there (with some variance) if the number of exposed cases is high enough.

Due to the long-term scientific focus on childhood leukemia, the number of childhood leukemia studies is considerably higher. The pooled results of 36 epidemiologic studies [5]-[40] irrespective the chosen exposure metrics are presented in Figure 3 in dependence on the number of exposed cases $\mathrm{N}_{\text {cases }}$. It is important to note that the overall pattern is similar to that seen in childhood cancer (Figure 2). Again, the reported OR values including "statistical significant" results are found on either side of the no-risk-line OR $=1$ indicating both increased as well as decreased risks.

Again, there is an offset of the body of results towards increased risk.

Again, statistical significant results are reported at lower numbers of exposed cases only. However, most interestingly, again, including results from meta-analyses it can be seen that with increasing number of exposed cases from either side significant as well as not significant OR values tend towards the no-risk-line OR $=1$ and stay there at further increasing number of exposed cases. Similar to the childhood cancer case (Figure 2) this indicates that there is no causal relationship.

This is supported by the fact that also the OR pattern from particular exposure metrics only (results not shown) revealed the same pattern.

As a further check, also the results of 5 epidemiologic studies on the use of electric appliances and childhood leukemia and childhood cancer were analyzed in the same way [39] [40] [49]-[51].

As shown in Figure 4 it is important to note that in pite of the inhomogeneous fields of appliance and, consequently the partial body exposure and the intermittend exposure rather than chronic whole-body exposure to residential fields the pattern of OR values in dependence of the number of exposed cases is quite similar to previous patterns.

Again, the reported OR values including "statistical significant" results are found on either side of the no-risk-line OR = 1 indicating both increased as well as decreased risks. Again, there is an offset of the body of results towards increased risk (OR $>1$ ). Again it can be seen that with increasing number of exposed cases from either side significant as well as not significant OR values tend towards the no-risk-line OR $=1$.

In addition, it is interesting and not at all self-evident to find that with regard to absolute values and trend even the results of electrical appliances fit well to the pattern of OR values of childhood leukemia. 


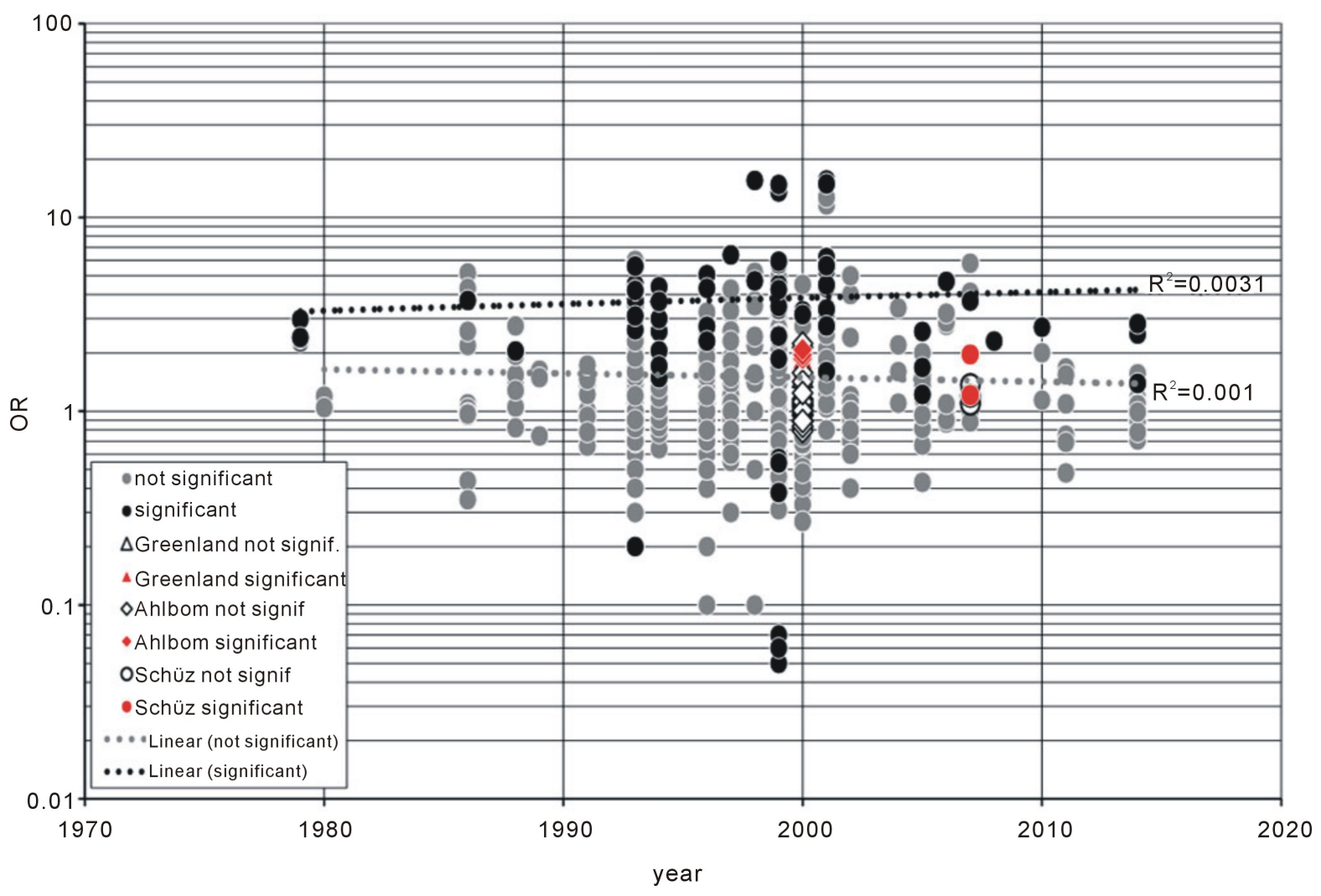

Figure 1. Odds ratios (OR) of of epidemiological studies on childhood leukemia over publication year (full symbolsstatistical significant, open symbols—not statistical significant; dotted-regression lines).

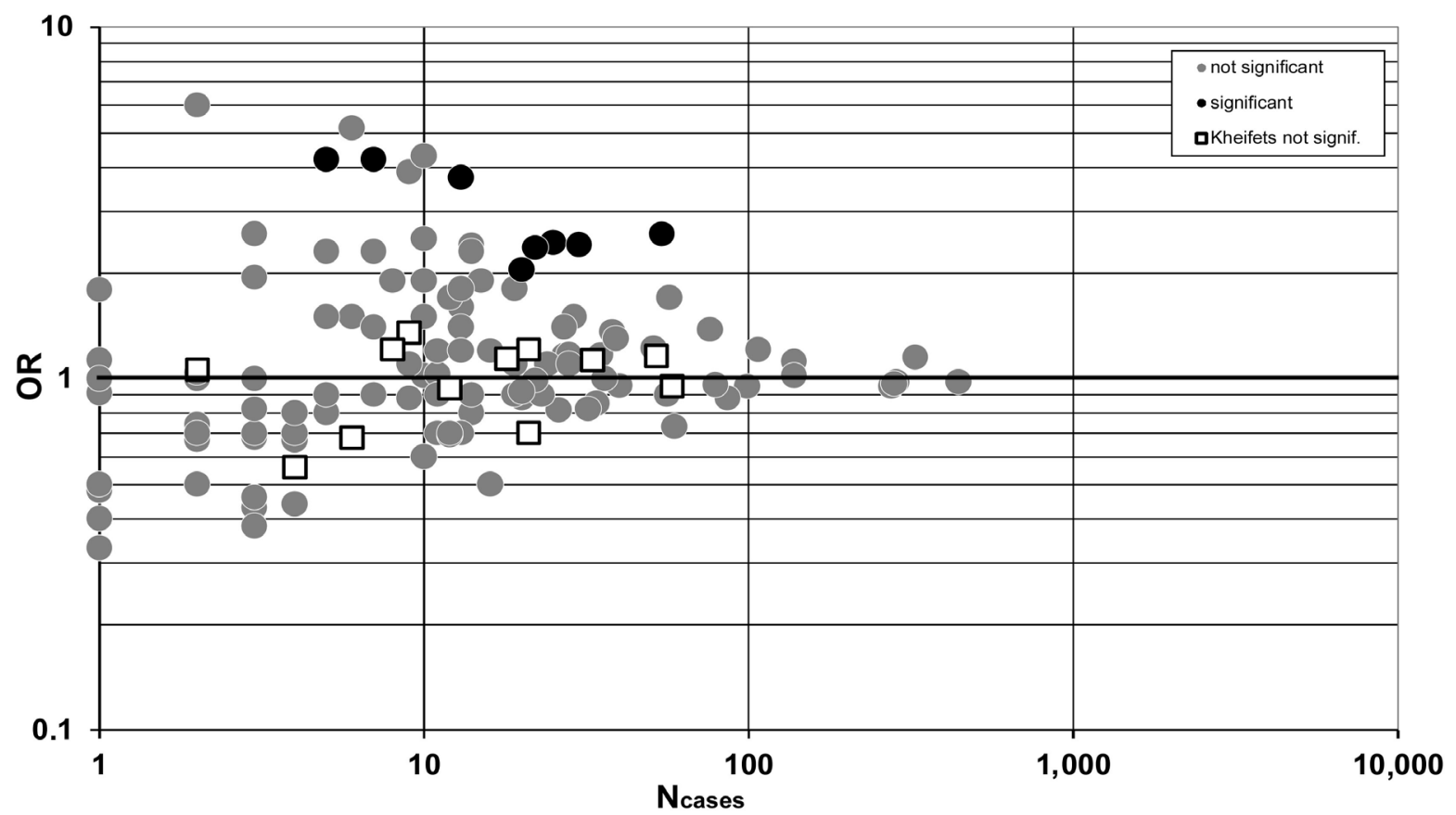

Figure 2. Odds ratios (OR) of epidemiological studies on childhood cancer (except leukemia) and residential magnetic fields of any exposure metric over the number of exposed cases cases (full black symbols - statistical significant, full grey symbols - not statistical significant, open symbols—statistical not significant results of meta-analyses). 


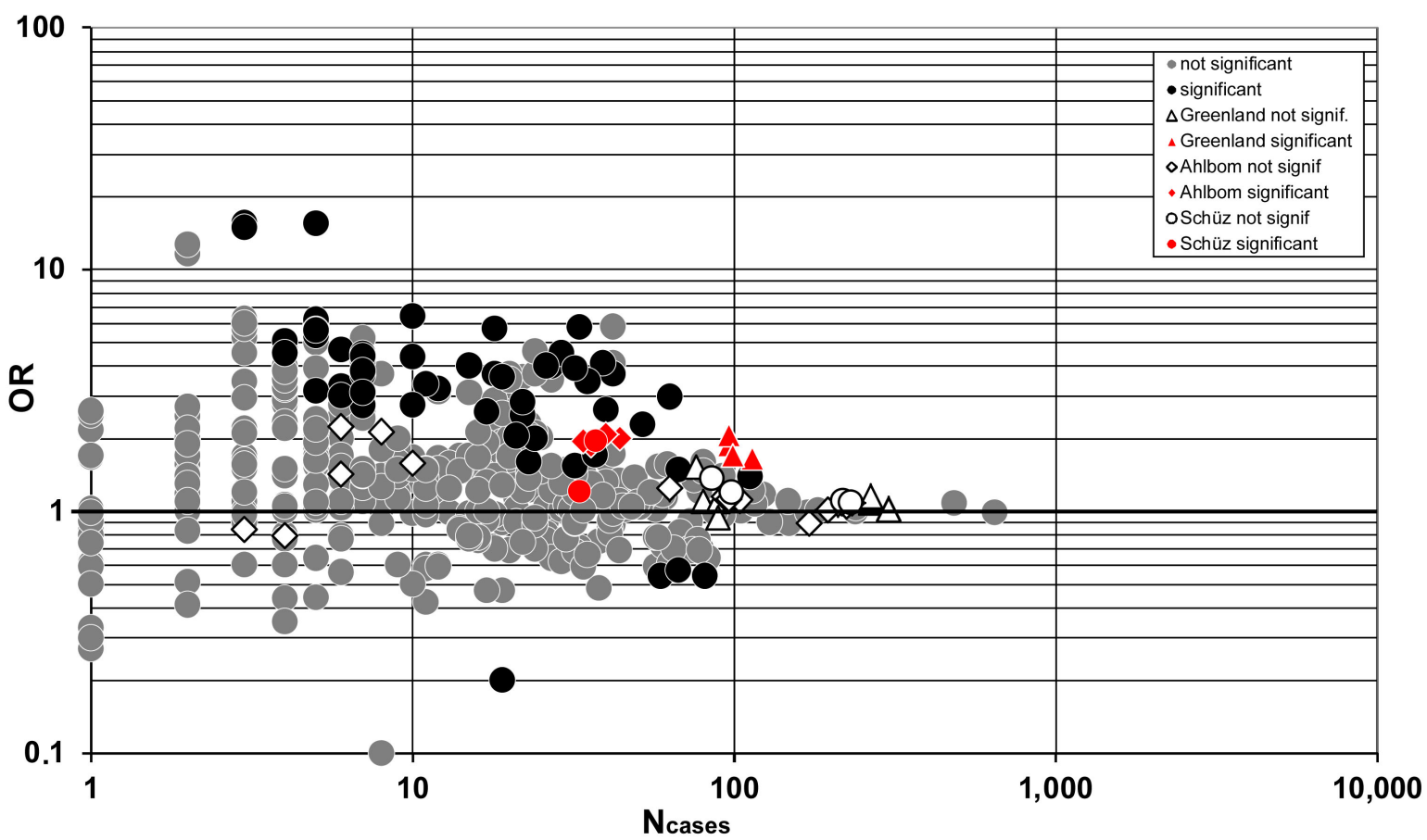

Figure 3. Odds ratios (OR) of epidemiological studies on childhood leukemia and residential magnetic fields of any exposure metric over number of exposed cases (full black symbols—statistical significant, full grey symbols-not statistical significant, red symbols_-statistical significant results of meta-analyses, open symbols—statistical not significant results of meta-analyses).

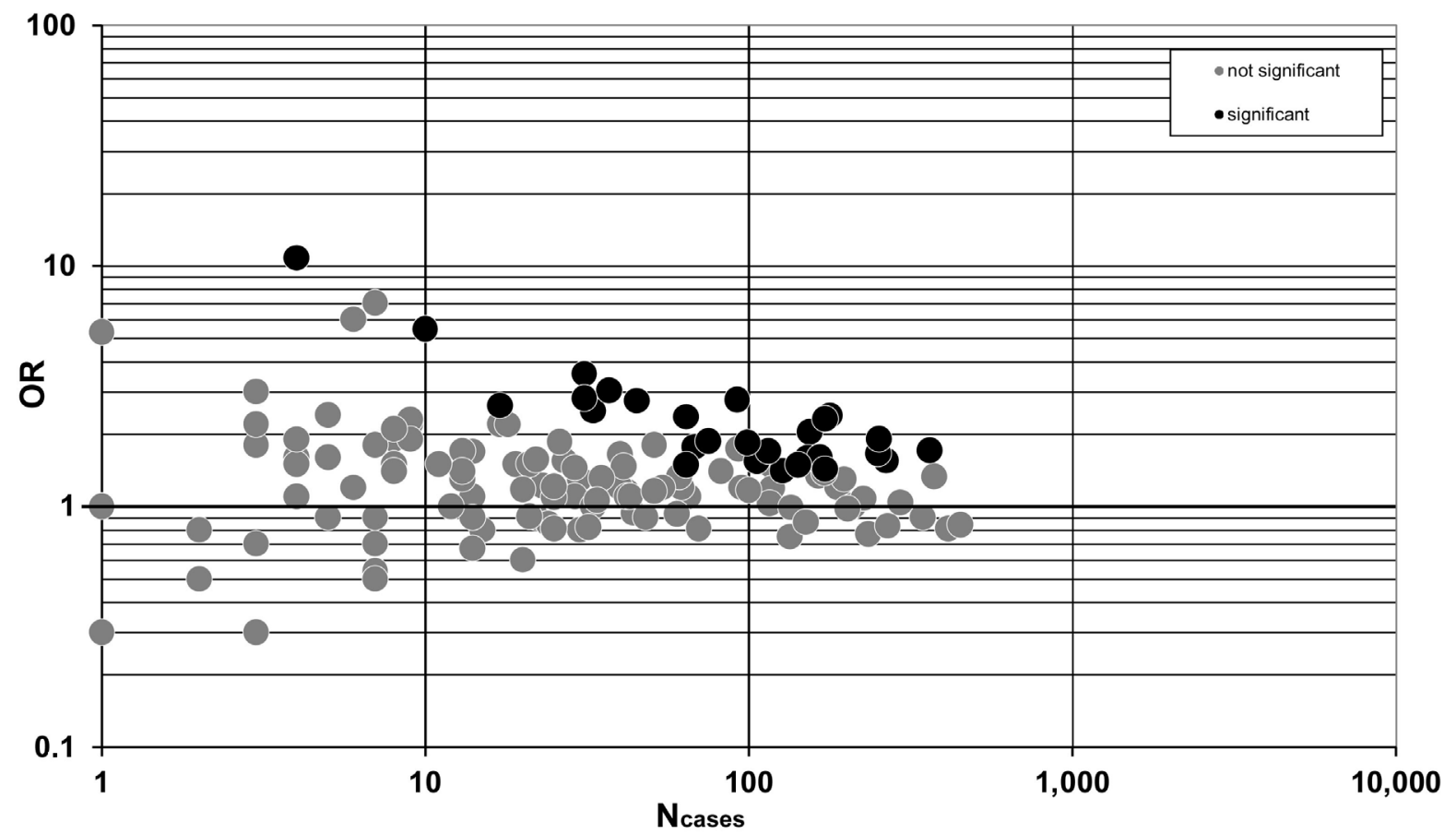

Figure 4. Odds ratios (OR) of epidemiological studies on childhood leukemia and the use of electrical appliances over number of exposed cases (full black symbols—statistical significant, full grey symbols—not statistical significant, red symbols—statistical significant results of meta-analyses, open symbols—statistical not significant results of meta-analyses). 


\section{Discussion}

The presented analysis has the major advantage that it does not need excluding any result. Since no mechanisms are known for long-term effects, in particular childhood leukemia, there is no rational for excluding a particular exposure metric nor justifying to rely on a particular one. By not needing to restrict to studies of the same study design only, it is possible to pool all the existing evidence together.

So far, in the discussion on a potential causal relationship between long-term exposure to ELF MF and biological endpoints such as cancer or leukemia, the reported OR were analyzed with little weight given to sudies's quite different statistical power. However, the presented figures show that among studies the number of exposed cases varies considerably from only very few to several hundreds. This is crucial.

The shown results demonstrate clearly that with increasing number of exposed cases the OR indicating reduced as well as enhanced risk tend towards the no-risk line $\mathrm{OR}=1$ and stay there with further increasing number. This is consistently seen independent from the investigated MF source, exposure metric, kind of exposure and even kind of investigated biologic endpoint.

This provides evidence for the lack of a causal relationship of EMF MF and cancer including childhood leukemia. This finding is supported by several facts:

1) the pattern seen in childhood leukemia (Figure 3) is the same as the pattern of brain cancer and other cancers (Figure 2) for which there is scientific agreement that there is no causal link to ELF MF;

2) the pattern for childhood leukemia seen with residential ELF MF (Figure 3) is the same as with ELF MF from electrical appliances (Figure 4) in spite of their quite different exposure regimes in terms of partial-body and intermittend short-term exposure to high(er) MF such as from hair dryers, computers, electrical beds etc.;

3) quite different exposure metrics of residential MF exposure are associated with same range and patterns of OR values irrespective whether exposure is characterized by surrogates, such as distance from MF source or wiring codes, or estimated field quantities such as those related to different points in time (e.g. prior diagnosis, at diagnosis, at study) and related to different intervals (e.g. year, daytime or nighttime) or to differently generated parameters (e.g. spot values, mean values, time-averages, accumulated excess of threshold values, time integrals, content of transients) etc.;

4) results of meta-analyses fit well with the overall pattern of OR values;

5) in spite of the much longer exposure times there is no evidence for a causal relationship between EMF MF exposure and adult cancers including leukemia (IARC 2002).

6) in spite of the suspicion that leukemia risk increases with field amplitude already above the onset value $0.2 \mu \mathrm{T}$ no causal relationship with any cancer could be found at workers with EMF MF exposures which were several orders of magnitudes higher [1] [3].

7) the hypothesis childhood-leukemia could be causally linked to ELF MF exposure is not supported by any other scientific approaches, neither by in-vitro nor by in-vivo studies;

8) a potential causal link of childhood leukemia with ELF MF cannot be explained by established physical or biological interaction mechanism.

However, there is still one important argument seemingly supporting the childhood-leukemia hypothesis, namely the dose-response relationship in terms of an almost exponential increase of OR values reported from $0.2 \mu \mathrm{T}$ until $0.4 \mu \mathrm{T}$. This was taken as a reason for concern [1] [3]. However, with the presented results, this can now be explained as a low-number effect. Since the number of exposed cases decreases with increasing MF exposure, and consequently this is associated with the tendency of reporting higher OR values this could be misinterpreted as dose-response.

This solves the dilemma of how to extrapolate hypothesized leukemia risk from the suspected cancer-risk onset level $0.2 \mu \mathrm{T}$ to the very much higher exposures such as from electric appliances or at workplaces which are even several orders of magnitudes higher.

This also solves the dilemma that exposure limits remained several orders of magnitudes above the suspected cancer-risk onset level without convincing justification.

The demonstrated lack of causality now explains why the same pattern is found at quite different exposure metrics and field sources in spite of the fact that inadequate metrics should have led to different results. In addition, the non-causality together with questionable choice of the level of statistical significance at multiparameter analysis explains the existence of controversial results and contradictory conclusions.

With regard to ELF MF it is good news that to the best of all our established knowledge the data show that a 
causal link between environmental ELF MF and childhood leukemia (and other cancer) can be excluded.

However, the question arises: How certain is certain enough? How many additional studies should be made to further support what seems now already convincingly clear? With regard to the overall pattern, it cannot be expected that more of the same, that more epidemiologic studies, that some more OR values could change the pattern of existing data which have now been collected for over 35 years since the first epidemiological study on childhood leukemia in 1979.

In addition, an important question remains: How safe is safe enough? Can the demand of some people be fulfilled to guarantee that nothing can happen, that no residual risk could be expected, that no future generation could come to quite different conclusions?

Obviously, this questions needs to be answered by politicians rather than by scientists. However, everybody, who buys a product is day by day necessarily making his or her own choice about which (limited) safety level is considered acceptable, and hardly spends the money to buy e.g. a car with the ultimate best available safety but makes reasonable compromises.

Since freedom of any risk can simply not be realized, neither yet nor in the future, in our laws safety is not defined as "no risk at all" but as the "level of acceptable residual risk". This could help accepting what the pool of data on epidemiologic studies on ELF MF and (childhood) cancer is telling us.

\section{Conclusion}

The new approach allowed pooled analyses of the entire body of epidemiologic data on a potential link between childhood leukemia and ELF MF. After 35 years of epidemiological research this now allows explaining puzzling facts such as that reported risk indicators (OR) are independent of the kind of exposure metric, the field source and even of chosen biologic endpoint. The presented overall analysis resulted in convincing evidence that similar to other childhood cancer and adult cancer there is also no causal relationship with childhood leukemia and ELF MF exposure. Therefore, the classification of ELF MF as possibly carcinogenic needs revision.

\section{Conflict of Interest}

The author declares no conflict of interest.

\section{References}

[1] IARC (2002) IARC Monographs on the Evaluation of Carcinogenic Risks to Humans. Non-Ionizing Radiation, Part 1: Static and Extremely Low-Frequency (ELF) Electric and Magnetic Fields, Vol. 80, Lyon.

[2] ICNIRP (2010) Guidelines for Limiting Exposure to Time-Varying Electric and Magnetic Fields (1 Hz to $100 \mathrm{kHz}$ ). Health Physics, 99, 818-836.

[3] WHO (2008) Environmental Health Criteria 238. Extremely Low Frequency Fields, WHO, Geneva.

[4] EU. Directive on the Minimum Health and Safety Requirements Regarding Exposure of Workers to the Risks Arising from Physical Agents (Electromagnetic Fields). Official Journal of the European Union, 179, 1-18.

[5] Wertheimer, N. and Leeper, N. (1979) Electric Wiring Configurations and Childhood Cancer. American Journal of Epidemiology, 109, 273-284.

[6] Ahlbom, A., Day, N., Feychting, M., Roman, E., Skinner, J., Dockerty, J., Linet, M., McBride, M., Michaelis, J., Olsen, J.H., Tynes, T. and Verkasalo, P.K. (2000) A Pooled Analysis of Magnetic Fields and Childhood Leukemia. British Journal of Cancer, 83, 692-698. http://dx.doi.org/10.1054/bjoc.2000.1376

[7] Greenland, S., Sheppard, A.R., Kaune, W.T., Poole, C. and Kelsh, M.A. (2000) A Pooled Analysis of Magnetic Fields, Wire Codes, and Childhood Leukemia. Epidemiology, 11, 624-634. http://dx.doi.org/10.1097/00001648-200011000-00003

[8] Schüz, J., Svendsen, A.L., Linet, M.S., McBride, M.L., Roman, E., Feychting, M., Kheifets, L., Lightfood, T., Mezel, G., Simpson, J. and Ahlbom, A. (2007) Nighttime Exposure to Electromagnetic Fields and Childhood Leukemia: An Extended Pooled Analysis. American Journal of Epidemiology, 166, 263-269. http://dx.doi.org/10.1093/aje/kwm080

[9] Kheifets, L., Ahlbom, A., Crespi, C.M., Feychting, M., Johansen, C., Mobroe, J., Murphy, M.F.G., Oksuzyan, S., Preston-Martin, S., Roman, E., Saito, T., Savitz, D., Schütz, J., Simpson, J., Swanson, J., Tynes, T., Verkasalo, P. and Mezel, G. (2010) A Pooled Analysis of Extremely Low Frequency Magnetic Fields and Childhood Brain Tumors. American Journal of Epidemiology, 172, 752-761. http://dx.doi.org/10.1093/aje/kwq181

[10] Fulton, J.P., Cobb, S., Preble, L., Leone, L. and Forman, E. (1980) Elecric Wiring Configurations and Childhood Leu- 
kemia in Rhode Island. American Journal of Epidemiology, 111, 292-296.

[11] Coleman, M.P., Bell, C.M.J., Taylor, H.L. and Primic-Zakeli, M. (1989) Leukemia and Residence near Electric Transmission Equipment: A Case-Control Study. British Journal of Cancer, 60, 793-798. http://dx.doi.org/10.1038/bjc.1989.362

[12] London, S.J., Thomas, D.C., Bowman, J.D., Soberl, E., Cheng, T.-C. and Peters, J.M. (1991) Exposure to Residential Electric and Magnetic Fields and Risk of Childhood Leukemia. American Journal of Epidemiology, 134, 923-937.

[13] Fajardo-Guitérrez, A., Garduno-Espinosa, J., Yamamoto-Kimura, L., Hernández-Hernández, D.M., Gómez-Delgado, A. and Martínez-Garcia, Md.C. (1993) Residencia Cercana a Fuentes Electrical de Alta Tension y su Asociación con Leukemia en Ninos. Boletín médico del Hospital Infantil de México, 50, 32-38.

[14] Lin, R.S. and Lee, W.C. (1994) Risk of Childhood Leukemia in Areas Passed by High Power Lines. Review on Environmenal Health, 10, 97-103. http://dx.doi.org/10.1515/REVEH.1994.10.2.97

[15] Lin, R.S., Lee, W.-C. and Li, C.-Y. (1996) Risk of Childhood Leukemia in Households near High Power Lines. Medical and Biological Engineering and Computing, 34, 131-132.

[16] Coghill, R.W., Steward, J. and Philips, A. (1996) Extra Low Frequency Electric and Magnetic Fields in the Bedplace of Children Diagnosed with Leukemia: A Case-Control Study. European Journal of Cancer Prevention, 5, 153-158. http://dx.doi.org/10.1097/00008469-199606000-00002

[17] Petridou, E., Trichopoulos, D., Kravaritis, A., Pourtsidis, A., Dessypris, N., Skalkidis, Y., Kogevinas, M., Kalmanti, V., Koliouskas, H., Panagiotou, J.P., Piperopoulou, F., Tzortzatou, F. and Kalapothaki, V. (1997) Electric Power Lines and Childhood Leukemia: A Study from Greece. International Journal of Cancer, 73, 345-348. http://dx.doi.org/10.1002/(SICI)1097-0215(19971104)73:3<345::AID-IJC7>3.0.CO;2-\#

[18] Michaelis, J., Schüz, J., Meinert, R., Menger, M., Grigart, J.P., Kaatsch, P., Kaletsch, U., Miesner, A., Stamm, A., Brinkmann, K. and Kärner, H. (1997) Childhood Leukemia and Electromagnetic Fields: Results of a Population-Based Case-Control Study in Germany. Cancer Causes and Control, 8, 167-174. http://dx.doi.org/10.1023/A:1018464012055

[19] Linet, M.S., Hatch, E., Kleinerman, R.A., Robinson, L.L., Kaune, W.T., Friedman, D.R., Secverson, R.K., Haines, C.M., Hartsock, C.T., Niwa, S., Wacholder, S. and Tarone, R. (1997) Residential Exposure to Magnetic Fields and Acute Lymphoblastic Leukemia in Children. New England Journal of Medicine, 337, 1-8. http://dx.doi.org/10.1056/NEJM199707033370101

[20] Li, C.Y., Lee, W.C. and Lin, R.S. (1998) Risk of Leukemia in Children Living near High-Voltage Transmission Lines. Journal of Occupational and Environmental Medicine, 40, 144-147. http://dx.doi.org/10.1097/00043764-199802000-00010

[21] McBride, M.L., Gallagher, R.P., Thériault, G., Armstrong, B.G., Tamaro, S., Spinellil, J.J., Deadman, J.E., Finchman, S., Robson, D. and Choi, W. (1999) Power-Frequency Electric and Magnetic Fields and Risk of Childhood Leukemia in Canada. American Journal of Epidemiology, 149, 831-842. http://dx.doi.org/10.1093/oxfordjournals.aje.a009899

[22] Green, L.M., Miller, A.B., Agnew, D.A., Greenberg, M.L., Li, J., Villeneuve, P.J. and Tibshirian, R. (1999) Childhood Leukemia and Personal Monitoring of Residential Exposures to Electric and Magnetic Fields in Ontario. Cancer Causes and Control, 10, 233-243. http://dx.doi.org/10.1023/A:1008919408855

[23] Green, L.M., Miller, A.B., Villeneuve, P.J., Agnew, D.A., Greenberg, M.L., Li, J. and Donelly, K.E. (1999) A CaseControl Study of Childhood Leukemia in Southern Ontario, Canada, and Exposure to Magnetic Fields in Residences. International Journal of Cancer, 82, 161-170. http://dx.doi.org/10.1002/(SICI)1097-0215(19990719)82:2<161::AID-IJC2>3.0.CO;2-X

[24] Skinner, J., Maslanyi, M.P., Mee, T.J., Allen, S.G., Simpson, J., Roman, E. and Day, N.E. (2000) Childhood Cancer and Residential Proximity to Power Lines. British Journal of Cancer, 83, 1573-1580. http://dx.doi.org/10.1054/bjoc.2000.1550

[25] Bianchi, N., Crosignani, P., Rovelli, A., Titterelli, A., Carnelli, C.A., Rossitto, F., Vanelli, U., Porro, E. and Berrino, F. (2000) Overhead Electricity Power Lines and Childhood Leukemia: A Registry-Based Case-Control Study. Tumori, 86, 195-198.

[26] Auvinen, A., Line, M.S., Hatch, E.E., Kleinerman, R.A., Robinson, L.L., Kaune, W.T., Misakian, M., Niwa, S., Wacholder, S. and Tarone, R.E. (2000) Extremely-Low Frequency Magnetic Fields and Childhood Acute Lymphoblastic Leukemia: An Exploratory Analysis of Alternative Exposure Metrics. American Journal of Epidemiology, 152, $20-31$. http://dx.doi.org/10.1093/aje/152.1.20

[27] Schüz, J., Grigat, J.P., Brinkmann, K. and Michaelis, J. (2001) Residential Magnetic Fields as a Risk Factor for Childhood Acute Leukemia: Results from a German Population-Based Case-Control Study. International Journal of Cancer, 91, 728-735. http://dx.doi.org/10.1002/1097-0215(200002)9999:9999<::AID-IJC1097>3.0.CO;2-D

[28] Mizoue, T., Onoe, Y., Moritake, H., Okamura, J., Sokejima, S. and Nitta, H. (2004) Residential Proximity to HighVoltage Power Lines and Risk of Childhood Hematological Malignancies. Journal of Epidemiology, 14, 118-123. 
http://dx.doi.org/10.2188/jea.14.118

[29] Kabuto, M., Nitta, H., Yamamoto, S., Yamaguchi, N., Akiba, S., Honda, Y., Hagihara, J., Isaka, K., Saito, T., Ojima, T., Nalamura, Y., Mizoue, T., Iti, S., Eboshida, A., Yamazaki, S., Sokejima, S., Kurokawa, Y. and Kubo, O. (2006) Childhood Leukemia and Magnetic Fields in Japan: A Case-Control Study of Childhood Leukemia and Residential Power-Frequency Magnetic Fields in Japan. International Journal of Cancer, 119, 643-650. http://dx.doi.org/10.1002/ijc.21374

[30] Rahman, H.I.A., Shah, S.A., Alias, H. and Ibrahim, H.M. (2008) A Case-Control Study on the Association between Environmental Factors and the Occurrence of Acute Leukemia among Children in Klang Valley, Malaysia. Asian Pacific Journal of Cancer Prevention, 9, 649-652.

[31] Sohrabi, M.R., Tarjoman, T., Abadi, A. and Yavari, P. (2010) Living near Overhead High-Voltage Transmission Power Lines as a Risk Factor for Childhood Acute Lymphoblastic Leukemia: A Case-Control Study. Asian Pacific Journal of Cancer Prevention, 11, 423-427.

[32] Wünsch-Filho, V., Pelissari, D.M., Barbieri, F.E., Sant’Anna, L., Oliviera, C.T., deMata, J.F., Tone, L.G., Lee, M.L., de Andréa, M.L.M., Bruniera, P., Epelman, S., Filho, V.O. and Kheifets, L. (2011) Exposure to Magnetic Fields and Childhood Acute Lymphocytic Leukemia in Sao Paolo, Brazil. Cancer Epidemiology, 35, 534-539.

[33] Tomenius, L. (1986) 50-Hz Electromagnetic Environment and the Incidence of Childhood Tumors in Stockholm County. Bioelectromagnetics, 7, 191-207. http://dx.doi.org/10.1002/bem.2250070209

[34] Savitz, D.A., Wachtel, H., Barnes, F.A., John, E.M. and Tvrdik, J. (1988) Case-Control Study of Childhood Cancer and Exposure to 60-Hz Magnetic Fields. American Journal of Epidemiology, 128, 21-38.

[35] Olsen, J.H., Nielsen, A. and Schulgen, G. (1993) Residence near High Voltage Facilities and Risk of Cancer in Children. British Journal of Cancer, 307, 891-895.

[36] Verkasalo, P.K., Pukkala, E., Hongisto, M.Y., Valjus, J.E., Järvinen, P.J., Heikkilä, K.V. and Koskenvou, M. (1993) Risk of Cancer in Finnish Children Living Close to Power Lines. British Medical Journal, 307, 895-899. http://dx.doi.org/10.1136/bmj.307.6909.895

[37] Feychting, M. and Ahlbom, A. (1993) Magnetic Fields and Cancer in Children Living near Swedish High-Voltage Power Lines. American Journal of Epidemiology, 138, 467-481.

[38] Draper, G., Vincent, T., Kroll, M.E. and Swanson, J. (2005) Childhood Cancer in Relation to Distance from High Voltage Power Lines in England and Wales: A Case-Control Study. British Medical Journal, 330, 1290-1293. http://dx.doi.org/10.1136/bmj.330.7503.1290

[39] Söderberg, K.C., Naumburg, E., Ander, G., Cnattingius, S., Ekbom, A. and Feychting, M. (2002) Childhood Leukemia and Magnetic Fields in Infant Incubators. Epidemiology, 13, 45-49. http://dx.doi.org/10.1097/00001648-200201000-00008

[40] Dockerty, J.D., Elwood, J.M., Skegg, D.C.G. and Herbison, G.P. (1998) Electromagnetic Field Exposures and Childhood Cancers in New Zealand. Cancer Causes and Control, 9, 299-309. http://dx.doi.org/10.1023/A:1008825220759

[41] Myers, A., Clayden, A.D., Cartwright, R.A. and Cartwright, S.C. (1990) Childhood Cancer and Overhead Powerlines: A Case-Control Study. British Journal of Cancer, 62, 1008-1014. http://dx.doi.org/10.1038/bjc.1990.428

[42] Wertheimer, N., Savitz, D.A. and Leeper, E. (1995) Childhood Cancer in Relation to Indicators of Magnetic Fields from Ground Current Sources. Bioelectromagnetics, 16, 86-96. http://dx.doi.org/10.1002/bem.2250160204

[43] Preston-Martin, S., Navidi, W., Thomas, D., Lee, P.J., Bowman, J. and Pododa, J. (1996) Los Angeles Study of Residential Magnetic Fields and Childhood Brain Tumors. American Journal of Epidemiology, 143, 105-119. http://dx.doi.org/10.1093/oxfordjournals.aje.a008717

[44] Gurney, J.G., Mueller, B.A., Davis, S., Schwartz, S.M., Stevens, R.G. and Kopecky, K.J. (1996) Childhood Brain Tumor Occurrence in Relation to Residential Power Line Configurations, Electric Heating Sources, and Electric Appliance Use. American Journal of Epidemiology, 143, 120-128. http://dx.doi.org/10.1093/oxfordjournals.aje.a008718

[45] Tynes, T. and Haldorsen, T. (1997) Electromagnetic Fields and Cancer in Children Residing near Norwegian HighVoltage Power Lines. American Journal of Epidemiology, 145, 219-226. http://dx.doi.org/10.1093/oxfordjournals.aje.a009094

[46] Cheng, K.K., Day, N., Cartwright, R., Craft, A., Birch, J.M., Eden, O.B., McKinney, P.A., Petro, J., Beral, V., Roman, E., Elwood, P., Alexander, F.E., Chilvers, C.E.D., Doll, R., Taylor, C.M., Greaves, M., Goodhead, D., Fry, F.A. and Adams, G. (1999) Exposure to Power-Frequency Magnetic Fields and the Risk of Childhood Cancer. The Lancet, 354, 1925-1931. http://dx.doi.org/10.1016/S0140-6736(99)10074-6

[47] Kroll, M.E., Swanson, J., Vincent, T.J. and Draper, G.J. (2010) Childhood Cancer and Magnetic Fields from HighVoltage Power Lines in England and Wales: A Case-Control Study. British Journal of Cancer, 103, 1122-1127. http://dx.doi.org/10.1038/sj.bjc.6605795

[48] Bunch, K.J., Keegan, T.J., Swanson, J., Vincent, T.J. and Murphy, M.F.G. (2014) Residential Distance at Birth from 
Overhead High-Voltage Power Lines: Childhood Cancer Risk in Britain 1962-2008. British Journal of Cancer, 110, 1402-1408. http://dx.doi.org/10.1038/bjc.2014.15

[49] Savitz, D.A., John, E.M. and Kleckner, R.C. (1990) Magnetic Field Exposure from Electric Appliances and Childhood Cancer. American Journal of Epidemiology, 131, 763-773.

[50] Preston-Martin, S., Hurney, J.G., Pogoda, J.M., Holly, E.A. and Mueller, B.A. (1998) Brain Tumor Risk in Children in Relation to the Use of Electric Blankets and Water Bed Heaters. American Journal of Epidemiology, 143, 1116-1122. http://dx.doi.org/10.1093/oxfordjournals.aje.a008688

[51] Hatch, E.E., Linet, M.S., Kleinerman, R.A., Tarone, R.E., Severson, R.K., Hartsock, C.T., Haines, C., Kaune, W.T., Friedman, D., Robinson, L.L. and Wacholder, S. (1998) Association between Childhood Acute Lymphoblastic Leukemia and Use of Electric Appliances during Pregnancy and Childhood. Epidemiology, 9, 234-245.

http://dx.doi.org/10.1097/00001648-199805000-00006 
Scientific Research Publishing (SCIRP) is one of the largest Open Access journal publishers. It is currently publishing more than 200 open access, online, peer-reviewed journals covering a wide range of academic disciplines. SCIRP serves the worldwide academic communities and contributes to the progress and application of science with its publication.

Other selected journals from SCIRP are listed as below. Submit your manuscript to us via either submit@scirp.org or Online Submission Portal.
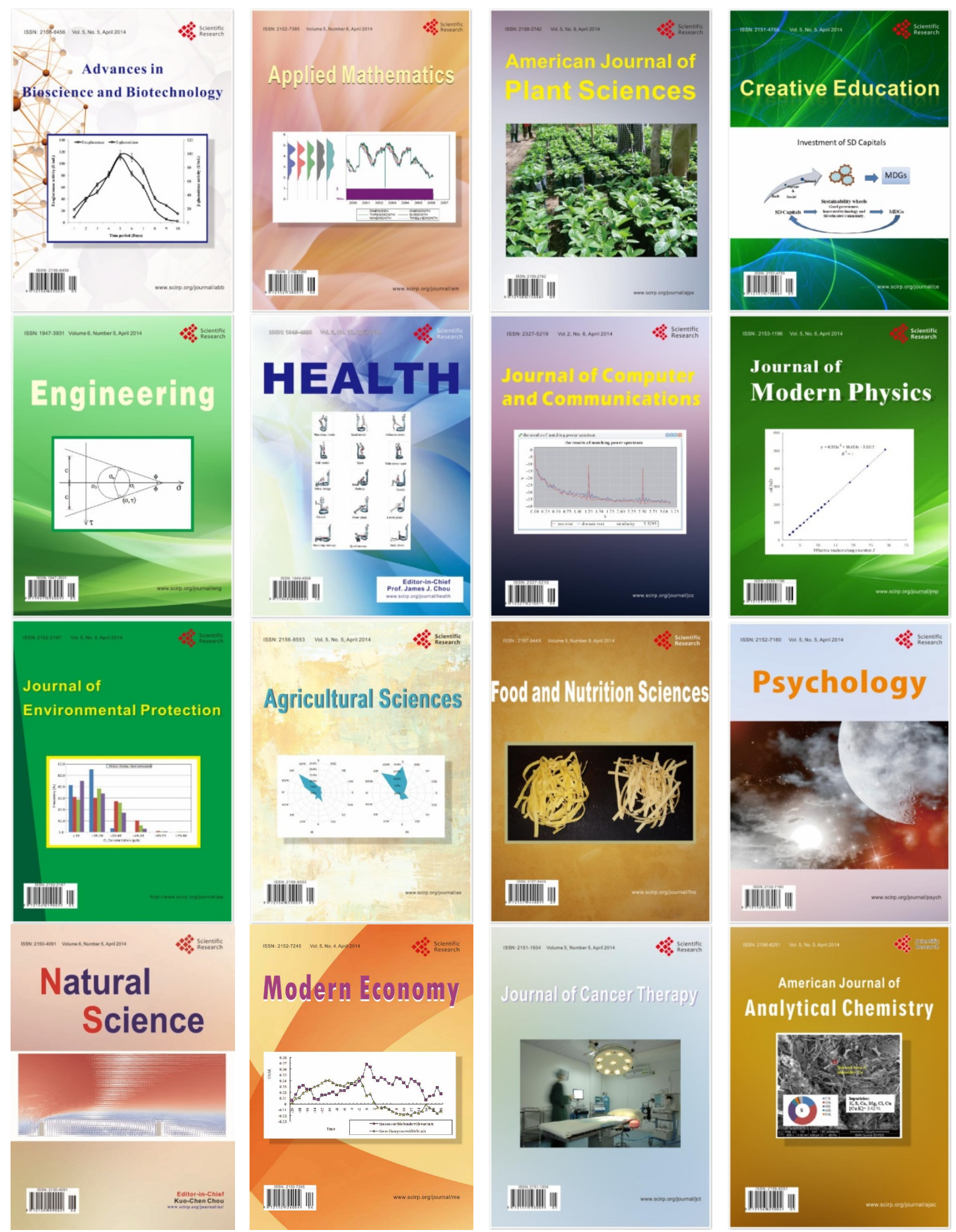